\title{
Intensity of land use by pasture as result of pedogeoclimatic characteristics and anthropogenic management
}

\author{
Arthur Calegario ${ }^{1}$, Demetrius da Silva ${ }^{1}$, Elpídio Fernandes Filho ${ }^{1}$, Roberto Filgueiras ${ }^{1}$, \\ Luis Flávio Pereira ${ }^{1}$, and Ana Luiza Rodrigues ${ }^{1}$ \\ ${ }^{1}$ Universidade Federal de Vicosa
}

December 1, 2021

\begin{abstract}
In the world, the most significant change in the ecosystems structure is the conversion from natural land surface into cultivated systems. In 2018, $26.8 \%$ of the Brazilian territory was occupied by agricultural activities, from which $73 \%$ is pasture. Considering that the management adopted in Brazilian pastures is incipient and leads to degradation, there is a need to characterize the state of the pastures to diagnose the intensity of this use on the soil. However, the diagnosis of large areas using satellites with more detailed resolution is limited by cloud coverage and low temporal resolution. In this sense, the present work aims to diagnose the intensity of land use by pastures (ILUP) in large areas based on the mosaic of images from Landsat 8 (LS8), Landsat 7 (LS7), Sentinel-2 (S2), and MODIS. The methodology consists of harmonizing the NDVI from LS7 and S2 satellites with LS8. For MODIS, the harmonization was carried out based on ILUP obtained previously from NDVI LS8. The methodology was applied at the Doce river basin (DRB). The combination of different sensors allowed to overcome the cloud coverage limitation. DRB has $61.3 \%$ of its area occupied by pastures and $78.2 \%$ of them have some degree of degradation. ILUP was dependent on DRB's pedological and climatic characteristics. This dependence is enhanced due to pasture management in the basin, mainly characterized by continuous grazing, which commonly leads to overgrazing scenarios. The areas with great rainfall seasonality and associated with Acrisols/Cambisols are the most susceptible to degradation.
\end{abstract}

\section{Hosted file}

C5A1 - Manuscript.docx available at https://authorea.com/users/448838/articles/547550intensity-of-land-use-by-pasture-as-result-of-pedogeoclimatic-characteristics-andanthropogenic-management 